\title{
Global warming impairs chemical communication between plants and pollinators
}

Guaraci Cordeiro ( $\nabla$ guaradc@gmail.com )

Paris-Lodron University of Salzburg

\section{Stefan Dötterl}

Paris-Lodron University of Salzburg

Article

Keywords: strawberry, bee pollinators, climate change

Posted Date: November 15th, 2021

DOI: https://doi.org/10.21203/rs.3.rs-1065160/v1

License: (c) (i) This work is licensed under a Creative Commons Attribution 4.0 International License. Read Full License 


\section{Abstract}

Global warming is expected to have a great impact on floral scents and consequently, on the attraction of pollinators. While there is evidence that temperature affects the biosynthesis and emission of floral scents, the effects on chemically mediated pollinator behavior have not been assessed. Here, we show by chemical analytical, electrophysiological, and behavioral approaches that increased air temperatures affect the chemical communication between strawberry (Fragaria $x$ ananassa) and its bee pollinators (Apis mellifera, Bombus terrestris, Osmia bicornis). Plants cultivated at increased temperatures released smaller amounts and a different composition of floral scent than plants cultivated at physiological optimum temperatures, which translated into a reduced attractiveness to pollinators. Our study highlights for the first time that increased temperatures negatively affect the chemical communication between plants and their pollinators. This raises important ecological and agricultural questions, as impaired communication between plants and their pollinators might result in insufficient pollination with negative consequences for ecosystem functioning and crop yields.

\section{Main Text}

The global Earth surface temperature is projected to increase by up to $5.7^{\circ} \mathrm{C}$ by the end of the $21 \mathrm{st}$ century, with heatwaves at this scale becoming increasingly frequent. This global warming has serious consequences for organisms, ecosystem functioning and food production ${ }^{1}$, while scientists worldwide are trying to understand the ecological effects of global warming on species interactions ${ }^{2,3}$. In plants, increased temperatures impair flower traits involved in communication with pollinators ${ }^{4,5}$. Among such traits are scents, which are released into the atmosphere through biochemical processes and play a key role in the attraction of pollinators ${ }^{6-9}$. The emission of scents by flowers is genetically determined ${ }^{10,11}$ but $^{-1}$ influenced by environmental factors. Flowers can emit a large array of scent compounds from several chemical classes (e.g., terpenoids, aromatic compounds) ${ }^{12}$. Temperature exerts a great impact on floral scents. Due to their low molecular weight and high vapor pressure, changes of a few degrees affect the vaporization of floral scent compounds $5,13,14$. In addition, physiological processes are influenced by temperature, and overall, temperature was shown to affect qualitative and quantitative scent properties ${ }^{15}$. Surprisingly, it is unknown whether and how this affects pollinator behavior and thus pollination in natural and agricultural settings.

Based on data collected in other contexts, it is known that quantitative and qualitative changes in floral scent emissions have effects on the attractiveness of the volatile signal to pollinators ${ }^{4,16,17}$. Indeed, the amount of flower scent released must be enough to reach at least the threshold to be detected by pollinators, whereas suboptimal amounts cause inefficient pollinator attraction ${ }^{18,19}$. It has been shown that flowers with higher floral scent emissions are often preferred by pollinators over flowers with lower emissions ${ }^{20,21}$. Qualitative changes in scent bouquets increase the probability that pollinators respond to the wrong signal ${ }^{17,22}$. 
Here, we used a combination of chemical analytical, electrophysiological, and behavioral approaches to quantify the effects of increased air temperatures on floral scent emissions of strawberry (Fragaria $x$ ananassa Duch - Rosaceae) and tested whether temperature-induced shifts in floral scent affect chemical communication with its main bee pollinators (Apis mellifera Linnaeus, Bombus terrestris Linnaeus, Osmia bicornis Linnaeus) ${ }^{23}$. Strawberry is an economically important crop cultivated worldwide ${ }^{24}$. To obtain good yields, pollination by bees is essential ${ }^{23,25}$. Strawberry plants were grown in plant-growth chambers under two temperature scenarios: physiological optimum (for growth and flowering) ${ }^{26}$ and $5{ }^{\circ} \mathrm{C}$ higher than optimal temperatures. Such an increase in temperature is predicted by the end of this century by the IPCC global warming scenario SSP-8.5 ${ }^{1}$. Sampling of scent samples was performed by dynamic headspace, and samples were analyzed using GC/MS (gas chromatography/mass spectrometry). After analyzing the floral scent profiles of the two temperature scenarios, the identified scent compounds were tested on the antennae of the pollinators by GC/EAD (gas chromatography coupled with electroantennographic detection) to evaluate the compounds eliciting physiological responses in the antennae of the bees. Physiologically active compounds were used to build scent mixtures that resembled the scent of plants grown at the different temperature scenarios. These mixtures were used for behavioral assays that tested for their attractiveness to bee pollinators.

Our results showed that temperature strongly affected the amount of scent released, with ninefold less scent emission at warmer than optimum temperatures $(9.55 \pm 2.16 \mathrm{ng} /$ flower/hour versus $1.06 \pm 0.59$ $\mathrm{ng} /$ flower/hour; $\mathrm{Z}=-3.14, \mathrm{~N}=19, \mathrm{p}=0.001$ ) (Table 1, Figure 1A). Temperature also influenced the number and composition (Pseudo- $\mathrm{F}_{1,18}=12.84, \mathrm{p}<0.001$ ) of compounds released by strawberry flowers, since plants grown at optimum temperatures emitted five compounds (four aromatic compounds and one sesquiterpene), whereas only 2 compounds (two aromatics) were detected in samples collected from plants cultivated at warmer temperatures. Plants in the optimum scenario released mainly the aromatic compound $p$-anisaldehyde (91\%), whereas plants in the warmer scenario released this compound to a lesser extent, but mainly the aromatic compound 1,4-dimethoxybenzene (83\%), a compound not detected in plants grown in the optimum scenario (Table 1, Figure 1B). All these compounds are widespread among bee-pollinated flowers ${ }^{8}$. Our findings are consistent with other studies that also found that floral scents change under heat stress ${ }^{6,27-29}$. In one study it was demonstrated that such changes are due to temperature dependent activities of enzymes and genes involved in the biosynthesis of scent compounds ${ }^{14}$. Overall, the floral scent strongly differed between the two different scenarios to an extent known not only within species but also among plant species ${ }^{8,30,31}$, suggesting that increased temperatures will strongly affect the communication between strawberry flowers and their pollinators.

Indeed, our electrophysiological recordings revealed that all three pollinator species are sensitive to at least five of the six flower scent compounds detected in the samples (Figure 2; see also ${ }^{32-34}$ ). Benzyl tiglate, which was not tested in our analyses, can also be sensed by bees, as previously shown by physiological measurements that tested the scent of apple flowers on honey bees ${ }^{35}$. Assuming that different receptors are involved in the detection of the different compounds, these findings altogether 
suggest that the bees very likely perceive the scent of the plants grown at the two different temperature scenarios differently.

In the behavioral experiments, all three bees preferred both optimum scent and warmer scent against negative controls and optimum scent against warmer scent (Figure 3$)$. Two ( $A$. mellifera, $B$. terrestris) of the three bee species were offered the same stimuli in a choice setting (optimum against optimum scent) and did not show a side bias. Therefore, the choices recorded in the tests, such as the reduced attractiveness of the warmer scent compared to the optimum scent, were indeed due to the stimuli, and not due to a side bias of the bees (Figure 3).

In a wild strawberry species, F. virginica, which releases 1-2 ng of scent per hour and produces hermaphrodite and female flowers, scent was also found to be important in pollinator attraction ${ }^{36}$. In this wild species, hermaphrodite flowers (ca. $1.8 \mathrm{ng} / \mathrm{h}$ ) emitted slightly more scent than female flowers (ca. $1.4 \mathrm{ng} / \mathrm{h}$ ), mainly due to the emission of 2-phenylethanol from stamens. This "small" difference was enough that female flowers received in the field only half as many bee pollinator visits as hermaphrodite flowers ${ }^{36}$. Thus, we predict that the observed strong decrease in the scent emission of cultivated strawberry grown under heat stress will result in the decreased attractiveness of the flowers to the pollinators, and it will have strong negative effects on the overall yield and fruit quality 23,25 .

\section{Conclusion}

Our study shows for the first time that increased temperatures predicted by global warming have not only strong negative effects on floral scent emissions but also on the attraction of pollinators. Together with the trend that modern crops emit fewer floral scents and are less attractive to pollinators than wild relatives ${ }^{37-39}$, this raises the important agricultural question of whether modern crops will continue to be sufficiently attractive to pollinators. It also raises the question of how increased temperatures will affect pollinator attraction in natural settings and influence ecosystem functioning. Currently, the molecular and biochemical processes in the biosynthesis of floral scent affected by heat stress are mostly unknown $5,14,40$, and therefore, more efforts are needed to elucidate the effects of increased temperatures on floral scent production and emission at a molecular level. This will help to develop breeding programs to increase the floral scent emissions of less heat-tolerant crops to avoid a mismatch with their pollinators and strong yield losses.

\section{Declarations}

\section{Acknowledgments}

This study was supported by a grant from the Austrian Science Fund (FWF; M2676-B29) to GDC and SD. We are grateful to Roman Fuchs for laboratory support and to Walter Gigerl for mechanical support with the growth chambers. We also thank the team of the Botanical Garten for help with the cultivation of 
strawberry plants, and the Plant Ecology lab members, specially Danae Laina, Herbert Braunschmid, Karin Gross, and Thomas Rupp for suggestions on an earlier version of the manuscript.

\section{Author contributions}

GDC and SD designed the study; GDC collected the samples and performed the experiments; GDC and SD analyzed the results; GDC and SD wrote the manuscript.

\section{Competing interests}

The authors declare no competing interests.

\section{References}

1. IPCC. Summary for Policymakers. In: Climate Change 2021: The Physical Science Basis.

Contribution of Working Group I to the Sixth Assessment Report of the Intergovernmental Panel on Climate Change [Masson-Delmotte, V., P. Zhai, A. Pirani, S. L. et al. (eds.)]. Cambridge University Press. In Press (2021).

2. Thackeray, S. et al. Phenological sensitivity to climate across taxa and trophic levels. Nature 535, 241-245 (2016).

3. Zamora-Gutierrez, V. et al. Vulnerability of bat-plant pollination interactions due to environmental change. Glob. Change Biol. 27, 3367-3382 (2021).

4. Burkle L.A. \& Runyon J.B. The smell of environmental change: Using floral scent to explain shifts in pollinator attraction. Appl. Plant Sci. 5, 1600123 (2017).

5. Borghi, M. et al. Flowers and climate change: a metabolic perspective. New Phytol. 224, 1425-1441 (2019).

6. Dobson, H.E.M. Relationship between floral fragrance composition and type of pollinator. In:

Dudareva N., Pichersky E., (eds), Biology of floral scent. CRC Press/Taylor and Francis Group, Boca Raton: 147-198 (2006).

7. Wiley, R.H. Signal detection and animal communication. Adv. Study Behav. 36, 217-247 (2006).

8. Raguso, RA. Wake up and smell the roses: the ecology and evolution of floral scent. Annu. Rev. Ecol. Evol. Syst. 39, 549-569 (2008).

9. Cordeiro, G.D. et al. Pollination of Campomanesia phaea (Myrtaceae) by night-active bees: a new nocturnal pollination system mediated by floral scent. Plant Biol. 19, 132-139 (2017).

10. Van Schie C.C.N., Haring M.A. \& Schuurink R.C. Regulation of terpenoid and benzenoid production in flowers. Curr. Opin. Plant Biol. 9, 203-208 (2006). 
11. Pichersky, E. \& Gang, D.R. Genetics and biochemistry of secondary metabolites in plants: an evolutionary perspective. Trends Plant Sci. 5, 439-445 (2000).

12. Knudsen J.T. et al. Diversity and distribution of floral scent. Bot. Rev. 72, 1-120 (2006).

13. Sagae M. et al. Effect of temperature on the floral scent emission and endogenous volatile profile of Petunia axillaris. Biosci. Biotechnol. Biochem. 72, 110-115 (2008).

14. Barman, M. \& Mitra, A. Floral maturation and changing air temperatures influence scent volatiles biosynthesis and emission in Jasminum auriculatum Vahl. Environ. Exp. Bot. 181, 104296 (2021).

15. Farré-Armengol, G. et al. Deciphering the biotic and climatic factors that influence floral scents: a systematic review of floral volatile emissions. Front. Plant Sci. 11, 1154 (2020).

16. Beyaert, I. \& Hilker, M. Plant odour plumes as mediators of plant-insect interactions. Biol. Rev. 89, 6881 (2014).

17. Larue, A.A.C., Raguso, R.A. \& Junker, R.R. Experimental manipulation of floral scent bouquets restructures flower-visitor interactions in the field. J. Anim. Ecol. 85, 396-408 (2016).

18. Arpaia, S. et al. Foraging activity of bumblebees (Bombus terrestris L.) on Bt-expressing eggplants. Arthropod Plant Interact. 5, 255-261 (2011).

19. Majetic, C.J., Raguso, R.A. \& Ashman, T.L. The sweet smell of success: floral scent affects pollinator attraction and seed fitness in Hesperis matronalis. Funct. Ecol. 23, 480-487 (2009).

20. Kessler, D., Gase, K. \& Baldwin, I.T. Field experiments with transformed plants reveal the sense of floral scents. Science 321, 1200-1202 (2008).

21. Parachnowitsch, A.L., Raguso, R.A., Kessler, A. Phenotypic selection to increase floral scent emission, but not flower size or colour in bee-pollinated Penstemon digitalis. New Phytol. 195, 667-675 (2012).

22. Morse, A. et al. The impact of greenhouse tomato (Solanales: Solanaceae) floral volatiles on bumble bee (Hymenoptera: Apidae) pollination. Environ. Entomol. 41, 855-864 (2012).

23. Klein, A. et al. Importance of pollinators in changing landscapes for world crops. Proc. Royal Soc. $B$ 274, 303-313 (2007).

24. FAOSTAT (2014). http://faostat3.fao.org/ Accessed 30 August, 2021.

25. Klatt, B.K. et al. Bee pollination improves crop quality, shelf life and commercial value. Proc. Royal Soc. B 281, 20132440 (2014).

26. Hytönen, T. \& Kurokura, T. Control of flowering and runnering in strawberry. Hort. J. 89, 96-107 (2020).

27. Farré-Armengol, G. et al. Changes in floral bouquets from compound-specific responses to increasing temperatures. Glob. Change Biol. 20, 3660-3669 (2014).

28. Hu, Z. et al. The emission of floral scent from Lilium 'siberia' in response to light intensity and temperature. Acta Physiol. Plant. 35, 1691-1700 (2014).

29. Cna'ani, A. et al. Petunia $\times$ hybrida floral scent production is negatively affected by high-temperature growth conditions. Plant Cell Environ. 38, 1333-1346 (2015). 
30. Jakobsen, H.B. \& Olsen, C.E. Influence of climatic factors on emission of flower volatiles in situ. Planta 192, 365-371 (1994).

31. Delle-Vedove, R., Schatz, B. \& Dufay, M. Understanding intraspecific variation of floral scent in light of evolutionary ecology. Ann. Bot. 120, 1-20 (2017).

32. Wadhams, L.J. et al. Discrimination of oilseed rape volatiles by honey bee: Novel combined gas chromatographic-electrophysiological behavioral assay. J. Chem. Ecol. 20, 3221-3231 (1994).

33. Dötterl, S. \& Vereecken, N. (2010) The chemical ecology and evolution of bee-flower interactions: a review and perspectives. Can. J. Zool. 88, 668-697.

34. Burger, $\mathrm{H}$. et al. Perception of floral volatiles involved in host-plant finding behaviour: comparison of a bee specialist and generalist. J. Comp. Physiol. A 199, 751-761 (2013).

35. Rachersberger, M. et al. Honeybee pollinators use visual and floral scent cues to find Apple (Malus domestica) flowers. J. Agric. Food Chem. 67, 13221-13227 (2019).

36. Ashman, T.L. et al. The scent of a male: the role of floral volatiles in pollination of a gender dimorphic plant. Ecology 86, 2099-2105 (2005).

37. Young, A.M. \& Severson, D.W. Comparative analysis of steam distilled floral oils of cacao cultivars (Theobroma cacao L., Sterculiaceae) and attraction of flying insects - implications for a Theobroma pollination syndrome. J. Chem. Ecol. 20, 2687-2703 (1994).

38. Ferrari, M.J. et al. Inbreeding effects on blossom volatiles in Cucurbita pepo subsp. texana (Cucurbitaceae). Am. J. Bot. 93,1768-1774 (2006).

39. Klatt, B.K. et al. Flower volatiles, crop varieties and bee responses. PLOS ONE 8, e72724 (2013).

40. Dudareva, N. et al. Biosynthesis, function and metabolic engineering of plant volatile organic compounds. New Phytol. 198, 16-32 (2013).

\section{Tables}

Table 1. Relative amount (\%; mean \pm standard error) of the different scent compounds emitted by strawberry flowers under optimum and warmer scenarios. Compounds are listed according to chemical class. KRI: Kovats retention index. All compounds were identified based on mass spectra and retention indices of authentic standards. For information about the total amount of scent released by the flowers, see Figure 1.

\begin{tabular}{lccc}
\hline Compounds & KRI & Optimum & Warmer \\
\hline $\begin{array}{l}\text { Aromatics } \\
\text { benzyl alcohol }\end{array}$ & 1037 & $3.4( \pm 1.4)$ & \\
\hline 1,4-dimethoxybenzene & 1168 & & $83.3( \pm 8.3)$ \\
\hline methyl salicylate & 1205 & $1.2( \pm 0.4)$ & \\
\hline$p$-anisaldehyde & 1265 & $91.3( \pm 3.7)$ & $16.7( \pm 8.3)$ \\
\hline benzyl tiglate & 1508 & $0.6( \pm 0.3)$ & \\
\hline Sesquiterpenes & & & \\
\hline$(E, E)-\alpha$-farnesene & 1514 & $3.5( \pm 2.6)$ & \\
\hline
\end{tabular}




\section{Methods}

\section{Crops species and pollinators}

Strawberry (Fragaria x ananassa Duch - Rosaceae, variety - Florian F1, Dürr-Samen company) is a fruit crop widely appreciated for its characteristic aroma and sweetness. Adequate bee pollination increases yield and fruit quality ${ }^{25}$. We used the main pollinators of strawberry for our experiments: Apis mellifera Linnaeus, 1758 (obtained from a local beekeeper), Bombus terrestris Linnaeus, 1758 (Biobest ${ }^{\circledR}$, Belgium), and Osmia bicornis Linnaeus, 1758 (Mauerbienenzucht ${ }^{\circledR}$, Germany $^{23}$.

Strawberry is a gender-dimorphic species with hermaphroditic and female flowers, but in contrast to wild strawberry ${ }^{36}$, we did not find an effect of flower sex on scent emission (total amount of scent: $Z=-0.32$, $\mathrm{N}=10, \mathrm{p}=0.761$; relative scent composition: Pseudo $\mathrm{F}_{1,9}=1.12, \mathrm{p}=0.323$ ) and thus did not discriminate between the flower sexes in the present study.

\section{Crop plant cultivation and temperature regime}

The strawberry plants were cultivated in plant growth chambers (Liebherr, Profi line, Germany; adapted with a multistage temperature controller, model TAR 1700-2, Elreha, Germany, and light timer switch,

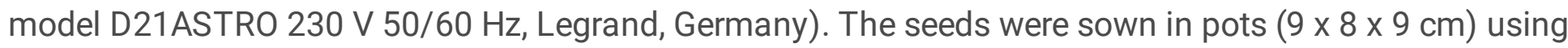
standard soil (Einheitserde ${ }^{\circledR}$, Profi Substrat) and fertilized once with $50 \mathrm{ml} /$ pot (Wufax ${ }^{\circledR}$, Nitrogen: 12\%, Phosphate: 4\%, Potassium: 6\%) when plants reached mid-age.

The requirements of strawberry plants for relative humidity (range between 60-70\%), light conditions, and water availability were controlled following literature data ${ }^{26}$. Plants were cultivated at $16 \mathrm{~h}$ light/08 $\mathrm{h}$ darkness. The light intensity was 2000 Ix (via cool white led lamps, model VT-5959 LED-Flutlicht, V-TAC, $50 \mathrm{~W}$ ). To keep the soil at comparable moisture levels during the development of the plants and between the different treatments, as measured by a tensiometer (model FDA 602 TM2, ALMEMO ${ }^{\circledR}$, Germany), the water supply varied according to the age of the plants and the temperature scenario. When they were sown, the amount was, independent of the scenario, $15 \mathrm{ml} /$ plant/day, in the mid-ages $60 \mathrm{ml} / \mathrm{plant} /$ day (optimum scenario) and $90 \mathrm{ml} / \mathrm{plant} /$ day (warmer scenario), and, during the flowering phase, 120 $\mathrm{ml} /$ plant/day (optimum scenario) and $170 \mathrm{ml} /$ plant/day (warmer scenario).

The plants were grown under two temperature scenarios: physiological optimum and $5^{\circ} \mathrm{C}$ higher than optimal temperatures (according the global warming scenario SSP-8.5, IPCC 2021). The physiological mean optimal temperature for the growth and flowering of cultivated strawberry ( $F$. ananassa) plants is $20^{\circ} \mathrm{C}^{26}$. Considering the mean daily thermal amplitude in Central Europe $\mathrm{e}^{41,42}$ and the optimal physiological temperatures, strawberry plants were cultivated in the optimal scenario at day and night with temperatures of $23^{\circ} \mathrm{C}$ and $13^{\circ} \mathrm{C}$ (mean $20^{\circ} \mathrm{C}$, when considering the length of the day and night 
periods), respectively, and in the warmer scenario, the temperatures were $28^{\circ} \mathrm{C}$ and $18{ }^{\circ} \mathrm{C}$ (mean $25^{\circ} \mathrm{C}$ ) during day and night, respectively. For each temperature scenario, 12 individual plants were cultivated.

\section{Sampling and analysis of flower scents}

Sampling of scent samples was performed inside the growth chambers by dynamic headspace. From 12 individuals cultivated for each scenario, 10 individuals of the optimum scenario and nine individuals of the warmer scenario produced flowers during the experiment and were sampled. The samples were always obtained from flowers on their first day of anthesis and between $10 \mathrm{am}$ and noon. A single flower per sample was enclosed in a polyester oven bag $\left(\right.$ Toppits $\left.^{\circledR}\right)$. After bagging, two small adsorbent tubes were inserted into the bag: one was used to trap the floral scent, and the other was used to insert clean air from outside of the growth chambers (to avoid internal air contamination). This sampling lasted $30 \mathrm{~min}$ using membrane pumps (G12/01 EB; Gardner Denver Thomas GmbH, Fürstenfeldbruck, Germany). The flows of both pumps were adjusted at $200 \mathrm{ml} / \mathrm{min}$ with the help of flowmeters. The adsorbent tubes (quartz vials, length: $25 \mathrm{~mm}$, inner diameter: $2 \mathrm{~mm}$ ) were filled with $1.5 \mathrm{mg}$ Tenax-TA (mesh 60-80) and $1.5 \mathrm{mg}$ Carbotrap B (mesh 20-40, both Supelco). The adsorbents were fixed in tubes using glass wool. Dynamic headspace samples of green leaves ( $\mathrm{N}=3$ samples per scenario) were collected with the same method to discriminate between vegetative (not considered for subsequent analyses) and flower-specific scent components. Samples from empty oven bags $(\mathrm{N}=3)$ were collected to identify potential contaminants.

Scent samples were analyzed using GC/MS (gas chromatography/mass spectrometry). The system consisted of an automated thermal desorption system (model TD-20, Shimadzu, Japan) coupled to a QP2010 Ultra EI GC/MS (Shimadzu, Japan) equipped with a Zebron ${ }^{\text {TM }}$ ZB-5 fused silica column (5\% phenyl 95\% dimethylpolysiloxane; $60 \mathrm{~m}$ long; inner diameter $0.25 \mathrm{~mm}$; film thickness $0.25 \mu \mathrm{m}$; Phenomenex), as described previously ${ }^{43}$. The GC/MS data were processed using GCMSsolution (Version 4.41, Shimadzu Corporation 2015). The tentative identification of compounds was carried out using the mass spectral libraries Wiley 9, Nist 2011/FFNSC 2, and Adams ${ }^{44}$, as well as the database available in MassFinder 3. The identity of all compounds was confirmed by a comparison of mass spectra and retention times with those of authentic standard compounds available at the Plant Ecology lab of the Paris-Lodron University of Salzburg. For estimation of total absolute scent emission per flower, we followed ${ }^{45}$.

Following identification and quantification of the floral scent compounds, synthetic mixtures (compounds that contributed at least $1 \%$ to the scent compositions of the two scenarios) that resembled the absolute and relative scent composition of the plants grown at the different temperature regimes were prepared to be used for electroantennographic detection. The mixture of the optimum scenario was composed of four compounds ( $99 \%$ of relative amount emitted; benzyl alcohol, methyl salicylate, $p$-anisaldehyde, $(E, E)$ - $a$ farnesene), the mixture of warmer scenario of two compounds ( $100 \%$ of relative amount emitted; $1,4-$ 
dimethoxybenzene, $p$-anisaldehyde). Benzyl tiglate, which was additionally released by plants under the optimum scenario, was not included in the mixture, as it was only found in trace amounts in some samples.

\section{Electroantennographic detection}

The synthetic scent mixtures of the different scenarios were tested on the antennae of the three bee pollinators ( $\mathrm{N}=7$ worker bee individuals each of $A$. mellifera and $B$. terrestris, and 5 females and 4 males of $O$. bicornis) by GC/EAD (gas chromatography coupled with electroantennographic detection) to evaluate the compounds eliciting antennal responses. The GC/EAD system, the same as that used by ${ }^{46}$, consisted of a gas chromatograph (Agilent 7890A, Santa Clara, California, USA) equipped with a flame ionization detector (FID) and an EAD setup (heated transfer line, 2-channel USB acquisition controller) provided by Syntech (Kirchzarten, Germany). A volume of $1 \mu \mathrm{l}$ of the samples was injected (temperature of injector: $250^{\circ} \mathrm{C}$ ) splitless at $40^{\circ} \mathrm{C}$ oven temperature, followed by opening the split vent after $0.5 \mathrm{~min}$ and heating the oven at a rate of $10^{\circ} \mathrm{C} \mathrm{min}^{-1}$ to $220^{\circ} \mathrm{C}$. A DMT Beta SE column (30 m long, inner diameter $0.25 \mathrm{~mm}$, film thickness $0.23 \mu \mathrm{m}, \mathrm{MEGA}-\mathrm{DEX}$ ) was used for the analyses, and the column flow (carrier gas: hydrogen) was set at $3 \mathrm{ml} \mathrm{min} \mathrm{m}^{-1}$. The column was split at the end by a $\mu$ Flow splitter (Gerstel, Mülheim, Germany) into two deactivated capillaries leading to the FID $(2 \mathrm{~m} \times 0.15 \mu \mathrm{m})$ and EAD $(1 \mathrm{~m} \mathrm{x}$ $0.2 \mu \mathrm{m})$ setups. Makeup gas $\left(\mathrm{N}_{2}\right)$ was introduced in the splitter at $25 \mathrm{ml} \mathrm{min}^{-1}$. The outlet of the EAD was placed in a cleaned and humidified airflow that was directed over the antenna of the pollinators. The antennae were cut at their base and tip, inserted between two electrodes filled with an insect ringer (8.0 $\mathrm{g} / \mathrm{l} \mathrm{NaCl}, 0.4 \mathrm{~g} / \mathrm{l} \mathrm{KCl}, 0.4 \mathrm{~g} / \mathrm{l} \mathrm{CaCl}_{2}$ ), and connected to silver wires as described previously ${ }^{47}$.

A floral compound was considered EAD-active in a bee species when it elicited a depolarization response in at least four individuals. After identification of the EAD-active compounds, synthetic mixtures considering only these compounds were prepared for behavioral experiments. When pipetted on filter papers (diameter $3.7 \mathrm{~cm}$; Whatman), sampled by dynamic headspace, and analyzed by GC/MS, these mixtures resembled the relative and absolute scent composition of the plants grown at the different temperature regimes. The synthetic scent mixtures were prepared with compounds available in the reference collection of the Plant Ecology lab of the Paris-Lodron University of Salzburg in the highest purity available (>90\%). The solvent to dilute the scent mixtures and used as a negative control (see below) was acetone (Sigma-Aldrich, 99.8\%).

\section{Behavioral experiments}

Behavioral assays were performed to test whether the differences in flower scent emissions from strawberry plants grown at the different temperature scenarios affect their olfactory attractiveness to bee pollinators. These assays were conducted outdoors ( $A$. mellifera, B. terrestris) and indoors (O. bicornis) at 
the Paris-Lodron University of Salzburg. Tests with O. bicornis were performed indoors, as weather conditions during their flight period did not allow testing outdoors.

The outdoor behavioral experiments were performed in a flight cage (wooden construction clamped with white gauze of $8 \times 4 \times 2.2 \mathrm{~m}$ ) in the Botanical Garden, the same as that successfully used with bees before ${ }^{35}$. In this flight cage, Reseda lutea (Resedaceae) continuously flowers and is used as a pollen and nectar resource. The scent mixtures were offered on artificial flowers in dual-choice assays, with a distance of $1.50 \mathrm{~m}$ between them. The artificial flowers were made of blue bond paper of $7 \mathrm{~cm}$ diameter and tied on wooden sticks. White filter paper of $1 \mathrm{~cm}$ diameter (Whatman), onto which a mixture was applied, was placed in the middle of the artificial flower (Supplementary Figure 1A and 1B).

The indoor behavioral experiments were performed in a small cage $(30 \times 30 \times 30 \mathrm{~cm})$ placed in an experimental room (temperature: $25^{\circ} \mathrm{C}$ ) that was illuminated by five T26 EVG Grolux lamps. For each experimental run (17 runs in total), we tested 10 individuals per time (males and females separately) for one hour. Bees were fed sugar water $(50 \%, \mathrm{w} / \mathrm{w})$ inside the cage in a small pot. The scent mixtures were offered in dual-choice assays on filter papers (diameter $3.7 \mathrm{~cm}$; Whatman) placed on aluminum foil on the bottom of the cage with a distance of $20 \mathrm{~cm}$ between them (Supplementary Figure 1C and 1D, Supplementary Video 1).

For each pollinator, we tested the optimum and warmer scents against negative controls (acetone) and against each other. To test for a potential side bias, scents of the optimum scenario were also tested against itself. The amounts of scent mixtures offered to pollinators were equivalent to 100 flowering plant individuals, i.e., representing a small crop area (Supplementary Table 1).

A dual-choice assay lasted for $1 \mathrm{~h}$, whereas the position of the artificial flowers/filter papers were changed and the scent mixtures were renewed after $30 \mathrm{~min}$. Bees that landed on artificial flower/filter paper were recorded and marked with a nontoxic pen (Posca ${ }^{\circledR}$ - Tokyo, Japan) to avoid counting an individual bee twice.

A specific assay was replicated until a minimum of 15 bees responded. Only in some assays with warmer scents versus the negative control was the number of responding bees smaller than 15 , although the number of replicates was the same as for tests with the optimum scenario (Figure 3 ).

\section{Data analysis}

Mann-Whitney U tests (PAST Version 2.17c) 48 and PERMANOVA (based on Bray-Curtis similarities of percentage contribution of single compounds to total scent ${ }^{49}$; Primer 6 Version 6.1 .15 \& Permanova Version 1.0.5) were used to test for differences in the total amount and relative composition, respectively, of scent per flower between the different temperature scenarios. SIMPER was used to determine the compounds most responsible for relative differences in scent between the two temperature scenarios 
(Primer 6 Version 6.1.15). Nonmetric multidimensional scaling (NMDS) in Primer, based on the BrayCurtis similarities, was used to graphically display similarities in scent among samples/scenarios. The dual-choice behavioral experiments were analyzed by exact binomial tests of goodness-of-fit using the spreadsheet provided by http://udel.edu/ mcdonald/statexactbin.html.

\section{References}

41. PlavcovÁ, E. \& KyselÝ, J. Evaluation of daily temperatures in Central Europe and their links to largescale circulation in an ensemble of regional climate models. Tellus A: Dyn. Meteorol. Oceanogr. 63, 763781 (2011).

42. Worldclim (2020) New 1-km spatial resolution climate surfaces for global land areas. Available at http://worldclim.org/version2

43. Mitchell, T.C., Dötterl, S. \& Schaefer H. Hawkmoth pollination and elaborate petals in Cucurbitaceae: the case of the Caribbean endemic Linnaeosicyos amara. Flora 216, 50-56 (2015).

44. Adams, R.P. Identification of Essential Oil Components by Gas Chromatography/Mass Spectrometry. Carol Stream, IL: Allured Publishing Corporation (2007).

45. Cordeiro, G.D. et al. Nocturnal floral scent profiles of Myrtaceae fruit crops. Phytochemistry 162, 193198 (2019).

46. Heiduk, A. et al. Ceropegia sandersonii mimics attacked honey bees to attract kleptoparasitic flies for pollination. Curr. Biol. 26, 2787-2793 (2016).

47. Dötterl, S. et al. 1,4-Dimethoxybenzene, a floral scent compound in willows that attracts an oligolectic bee. J. Chem. Ecol. 31, 2993-2998 (2005).

48. Hammer, Ø., Harper, D.A.T. \& Ryan, P.D. PAST: Paleontological Statistics Software Package for Education and Data Analysis. Palaeontol. Electron. 4, 1-9 (2001).

49. Clarke K.R. \& Gorley R.N. Primer v6: user manual/tutorial. Primer-E, Plymouth, 1-91 (2006).

\section{Figures}



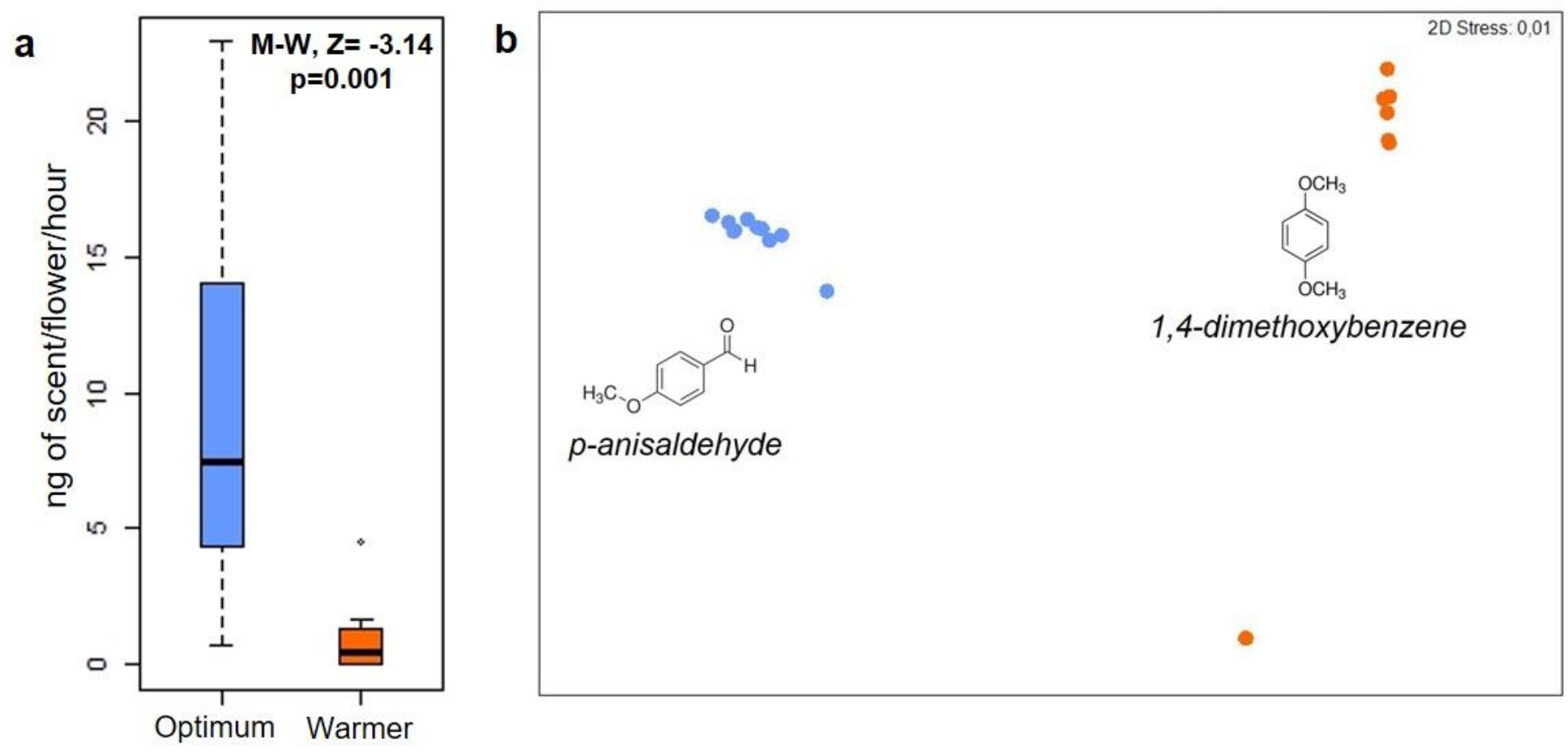

\section{Figure 1}

a-Total absolute amount of scent (ng of scent per hour and per flower) emitted by strawberry under optimum (blue) and warmer (orange) scenarios. b-Nonmetric multidimensional scaling (NMDS) used to display semiquantitative differences in scent profiles among strawberry scent samples collected under optimum (blue) and warmer (orange) scenarios. Compounds indicated in b were most responsible for differences in scent composition between the two temperature scenarios according to a SIMPER analysis. M-W: Mann-Whitney U tests. 


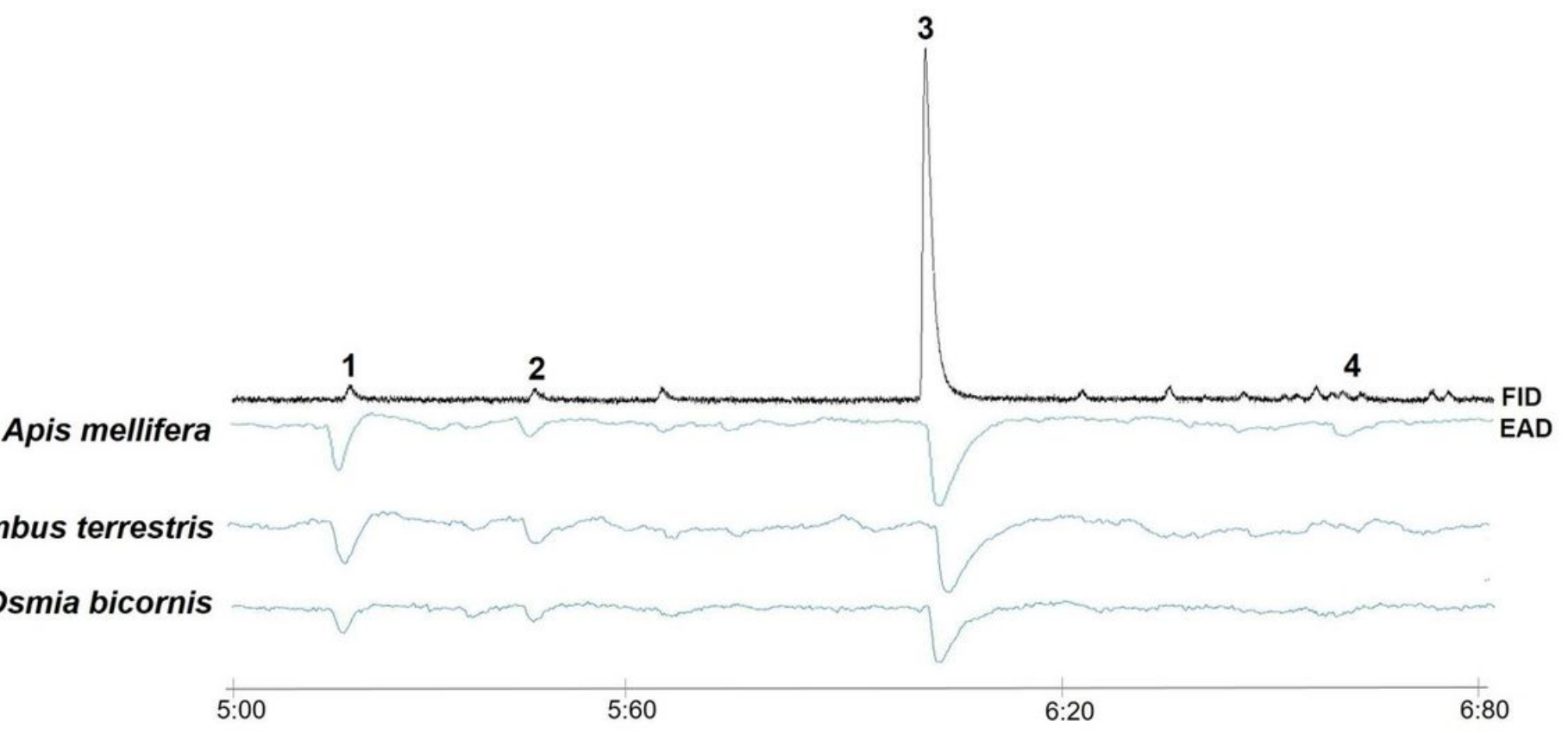

b

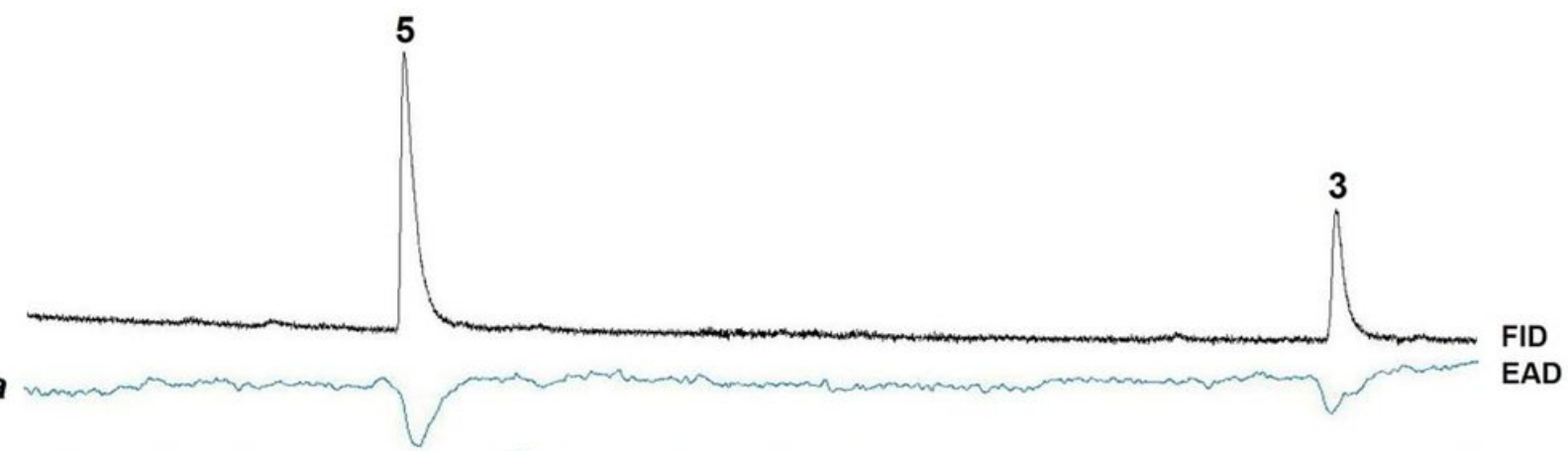

\section{Bombus terrestris}

Osmia bicornis
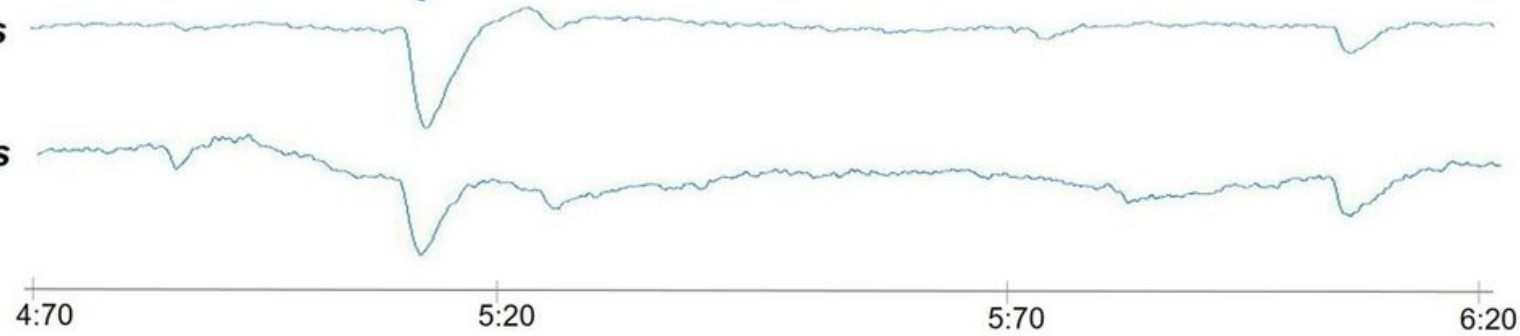

\section{Figure 2}

Examples of antennal responses (EADs) of Apis mellifera, Bombus terrestris, and Osmia bicornis to synthetic mixtures resembling the flower scent (FID) of strawberry (Fragaria $x$ ananassa) under optimum (a) and warmer (b) scenarios. 1. methyl salicylate, 2. benzyl alcohol, 3. p-anisaldehyde, 4. (E,E)-afarnesene, 5. 1,4-dimethoxybenzene. Compounds not numbered were contaminants. 


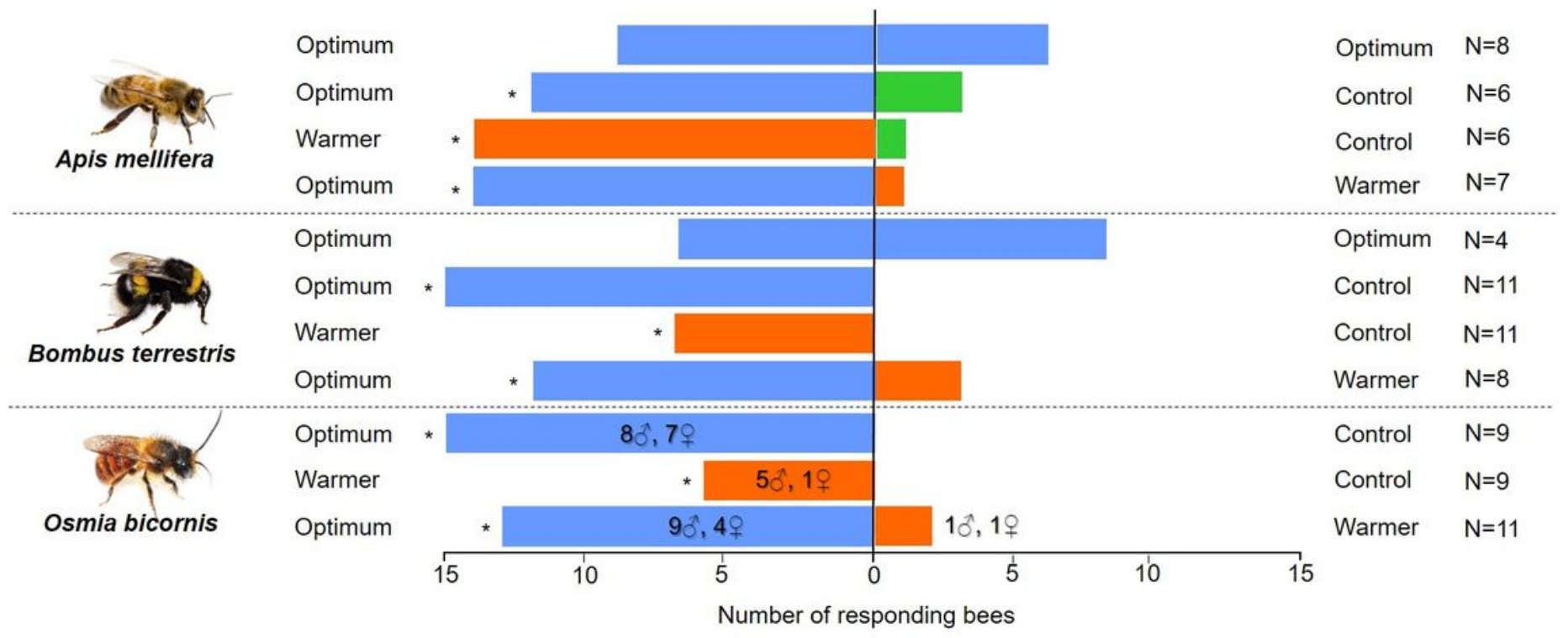

Figure 3

Pollinators' behavioral responses in dual-choice assays to synthetic mixtures resembling the flower scent of strawberry (Fragaria $x$ ananassa) under optimum (blue) and warmer (orange) scenarios. Negative controls (green) consisted only of the solvent used to dilute the scent compounds. Workers of Apis mellifera and Bombus terrestris, and males and females of Osmia bicornis were used for the experiments. *: the two choices were differently attractive according to an exact binomial test of goodness-of-fit. $N=$ number of replicates for each dual-choice assay.

\section{Supplementary Files}

This is a list of supplementary files associated with this preprint. Click to download.

- Supplementarymaterialfinal.docx

- VIDbioassayOsmia.mp4 